\title{
Aloe Vera Ameliorates Ovarian Toxicity Induced by Bisphenol A in Wistar Rats
}

\author{
Mohammad Amin Behmanesh ${ }^{1}$, Seyedeh Mahsa Poormoosavi ${ }^{1,2 *}{ }^{\mathbb{D}}$, Sima Janati ${ }^{2,3}$, \\ Hosein Najafzadehvarzi ${ }^{4}$ iD, Ehsan Sangtarash ${ }^{5}$
}

1. Dept. of Histology, Faculty of Medicine, Dezful University of Medical Sciences, Dezful, Iran

2. Research and Clinical Center for Infertility, Dezful University of Medical Sciences, Dezful, Iran

3. Dept. of Obstetrics and Gynecology, Faculty of Medicine, Dezful University of Medical Sciences, Dezful, Iran

4. Dept. of Pharmacology, Faculty of Medicine, Babol University of Medical Sciences, Babol, Iran

5. Faculty of Medicine, Dezful University of Medical Sciences, Dezful, Iran

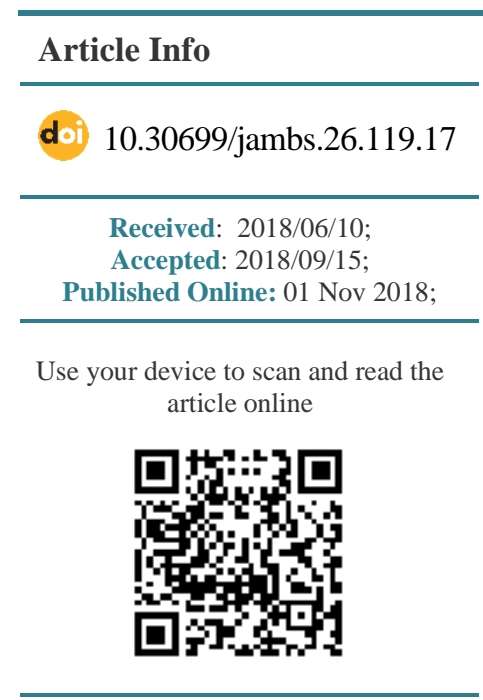

Corresponding Information: Seyedeh Mahsa Poormoosavi, Dept. of Histology, Faculty of Medicine, Dezful University of Medical Sciences, Dezful, Iran

Email: m.poormoosavi@ymail.com

\begin{abstract}
Background \& Objective: Bisphenol A (BPA) is a hazardous environmental pollutant, which is known to cause ovarian toxicity. The present study aimed to assess the protective effects of Aloe vera herbal extract against ovarian toxicity caused by BPA in Wistar rats.
\end{abstract}

Materials \& Methods: The sample population of this experimental study consisted of 40 adult female Wistar rats with a mean weight of $200 \pm 20$ grams. The test animals were investigated in five groups after synchronizing, including one control group and one vehicle group (olive oil $5 \mathrm{ml} / \mathrm{kg}$ b.wt./day). Rats in the experimental groups were administered with various oral doses of BPA and Aloe vera extract daily for eight consecutive weeks (400 mg Aloe vera gel/kg b.wt./day, $10 \mathrm{mg} \mathrm{BPA} / \mathrm{kg}$ b.wt./day dissolved in $5 \mathrm{~mL} / \mathrm{kg}$ of olive oil, and BPA + Aloe vera $)$. Blood samples $(2 \mathrm{~mL})$ were obtained from anesthetized rats after the intervention in order to measure the levels of oxidative stress markers and sex hormones. Moreover, the researchers collected both ovaries for histological examinations.

Results: BPA decreased estradiol levels significantly $(P<0.05)$. In addition, while thiol protein $(\mathrm{G}-\mathrm{SH})$ and total antioxidant capacity (TAC) decreased, malondialdehyde (MDA) showed an increase. Fewer corpus luteum and antral follicles, more atretic follicles and several cysts were observed in histopathological results of BPA group. But total antioxidant capacity and ovarian tissue healing structure were accelerated by coadministration of Aloe vera with BPA.

Conclusion: According to the results, the use of herbal extract of Aloe vera could significantly inhibit the debilitating effects of BPA on the reproduction of female rats. Moreover, Aloe Vera gel exerted protective effects against folliculogenesis, stimulating the production of hormones to prevent the toxicity caused by BPA.

\section{Introduction}

Environmental contamination with perilous chemicals, can impose adverse effect on humans and wildlife. During the last two decades it has become evident that environmental pollution disrupts female reproduction of wildlife and humans. In this regard, Bisphenol A (BPA) is among the most threatening pollutants that has been shown to disrupt the endocrine system. BPA is one of the main elements in plastic baby bottles and food and beverage containers. Humans are prone to a direct risk of BPA exposure as it can leach out to food or water from the polymers (1). In rodents, BPA can have an effect on indices of the reproductive functions such as egg deformation, ovary and uterus weights, and fertilization rates. Ovary atrophy increase in the atretic follicles and reduction in the antral follicles have also been observed in BPA administration (2).
Furthermore, reactive oxygen species (ROS) may be generated by various environmental pollutants that could cause oxidative stress. There are some publications which suggest that BPA can generate ROS (3). The production of ROS in living organisms stimulate antioxidant activities that diminish the effects of oxidative stress. Cells may contain endogenous and exogenous antioxidants, such as flavonoids. Recent findings have confirmed the antioxidant activity of numerous medicinal plants and herbs, such as Aloe vera, a plant with taut lance-shaped leaves of gray or green, which contain a clear gel in a central mucilaginous pulp (4). In some studies, it is shown that Aloe vera reduces fat oxidation and oxidative stresses (4). Furthermore, Aloe vera is able to enhance the bioavailability of vitamins $\mathrm{C}$ and $\mathrm{E}$, which are considered to be significant 
antioxidants (5). This medicinal plant has remarkable anti-inflammatory, anti-ulcer, chemo-preventive, antibacterial, and anti-tumor properties, which has been proven extremely effective in healing burn wounds (6). In females, the use of Aloe vera is associated with the sustained status of ovarian steroid in polycystic ovary syndrome, along with its beneficial treatment of infertility (7). Studies have also revealed that Aloe vera gel helps maintain the ovarian steroid status in polycystic ovary syndrome. For instance, conditions that altered and disturbed estrogen and testosterone ratio in steroidogenesis, along with the infertility of women could be treated (7). The present study was designed to examine the protective function of Aloe vera gel on the rat's ovary tissue and sex hormones, following BPA exposure in polycystic ovary syndrome.

\section{Materials and Methods}

\section{Animal Housing}

Forty adults female Wistar rats aged in the range of 10- 12 weeks (initially weighting $200 \pm 20 \mathrm{~g}$ ) were obtained from Dezful University of Medical Sciences Animal House (Dezful, Iran), and were used in a completely randomized experimental design. All the animals were preserved within a light/dark cycle for 12 hours at the temperature of $25 \pm 2^{\circ} \mathrm{C}$. Furthermore, access to water and food was granted throughout the research phases. This study was approved by Dezful University's Ethics Committee, (IR.DUMS.REC.1395.4) and all standards of safe animal testing were respected in the study procedures.

\section{Animal grouping}

Test animals were transferred to the laboratory one week before the study. All the rats were synchronized by PMSG (Fariman Co. Iran) and HCG (Intervet Holand) (40IU/rat) one week before sampling. Afterwards, the rats were classified into five groups of eight. All were treated orally on a daily basis for 8 weeks. In addition to the control group (normal saline), the animals in group 2 (vehicle) received $5 \mathrm{ml} / \mathrm{kg}$ b.wt./day of olive oil (8). The subjects in group 3 were administered with $400 \mathrm{mg}$ of Aloe vera gel $(\mathrm{kg}$ b.wt./day) (9), group 4 (10 $\mathrm{mg} \mathrm{BPA} / \mathrm{kg}$ b.wt./day) dissolved in $5 \mathrm{ml} / \mathrm{kg}$ olive oil (10), and group 5 (BPA+ Aloe vera gel with the mentioned dose). Bisphenol A with $97 \%$ purity (CAS No. 80-05-7) (Sigma, Aldrich Co., USA) was used in the vehicle group (olive oil solution). The Aloe vera gel was prepared by Barij Essence Company, (Iran), in which leaves were transversely cut into pieces and the thick epidermis layer removed. The solid gel in the leaf's center was homogenized and Aloe vera gel was prepared. HPLC was performed to detect and control the extract.

\section{Sample Collection}

After 24 hours of the last administration, $30 \mathrm{mg} / \mathrm{kg}$ of sodium thiopental was used to anesthetize the test animals.
The animals were killed after weight measurement. In the next step, a syringe ( $2 \mathrm{ml}$, without anticoagulant) was used to obtain heart blood samples from the animals and a serum was collected through centrifugation at $3000 \mathrm{rpm}(10$ minutes) and stored at $-20^{\circ} \mathrm{C}$ for analysis.

\section{Ovary Tissue Preparation and Histomorphometry}

After weight measurements, the collected samples of the animals' ovaries were set in a $10 \%$ formalin saline, and cross-sections (5-6 $\mu \mathrm{m})$ were provided (interval: 20 $\mu \mathrm{m})$ through paraffin embedding techniques using a rotary microtome (RM2235, Leica Company from USA). Sections were stained by hematoxylin-eosin for structure analysis of the ovary as well as histopathological examination. Meanwhile, photos were taken of the sections for histomorphometric analysis aims through the use of an Olympus optical microscope equipped with a Dino-lite camera at a magnification of $4 \times, 10 \times$, and $40 \times$, with the Dino-lite software being used for data extraction. Primary, secondary, and primordial follicles were measured in numbers at $40 \times$, whereas antral and artesian follicles were counted at a $10 \times$ microscopic magnification. The diameter of follicles containing oocyte with germinal vesicles were measured in each animal; 3 sections from one animal in each group and 3 randomly chosen areas in each section.

\section{Serum Sample and Biochemical Test}

The collected serum samples were utilized for the estimation of biochemical markers such as the amount of malondialdehyde (MDA) (11), to estimate lipid peroxidation, thiol protein $(\mathrm{G}-\mathrm{SH})(\mathbf{1 2})$, and total antioxidant capacity (TAC) (9). Furthermore, the mentioned criteria were used to assess oxidative stress. The required materials were products of Merck Company, Germany.

\section{Hormonal Assays}

Levels of progesterone and 17 beta-estradiol were measured in serum samples using an enzyme-linked immunosorbent assay. Concentration of 17 beta estradiol was measured by ELISA kit (ab108667), purchased from Abcam Company (USA). The progesterone concentration was measured by ELISA kit (SE120087), purchased from Sigma-Aldrich Company (USA).

\section{Statistical Analyses}

Data analysis was performed in SPSS 16 using a oneway analysis of variance (ANOVA) to determine the variances in the study groups and a Fisher's least significant difference test (LSD) to evaluate the differences between the groups. In all the statistical analysis, a P-value of $\leq 0.05$ was considered significant.

\section{Results}

Effects of Independent BPA Exposure and with Aloe vera Administration on the Body and Ovary Weight

Measured weight of the animal body and ovaries in the control and experimental groups is presented in Table 1. Our findings indicated no significant difference 
$(P>0.05)$ in the final body weight of BPA, BPA + Aloe vera, Aloe vera and olive oil groups when compared to the control group. Ovarian weight was also not modified by BPA exposure.

The effect of BPA on sex steroid hormone production is listed in Table 2. As shown in Table 2, BPA exposure significantly decreased estradiol compared to the control group $(P \leq 0.05)$. However, the administration of Aloe vera to BPA treated rats resulted in a compensated of the control level. BPA administration caused an insignificant reduction in progesterone concentration $(P>0.05)$.

Table 3 represents the serum biomarkers related to antioxidative status in the various groups. According to the results, animals of the BPA group had significantly higher MDA serum levels compared to that of the control group $(P \leq 0.05)$. Moreover, TAC and G-SH were significantly reduced in BPA treated rats $(P \leq 0.05)$. Administration of Aloe vera to $\mathrm{BPA}$ treated rats significantly reduced MDA compared to that of the BPA group $(P \leq 0.05)$. Aloe vera also increased $(P \leq 0.05)$ the level of G-SH and TAC in the BPA+Aloe vera group compared to that of BPA alone. It is worthy to note that independent Aloe vera supplementation has a significant effect $(P \leq 0.05)$ on serum antioxidative status of rats in comparison to the control group.

In Table 4, the effects of unaccompanied BPA exposure and BPA exposure with Aloe vera administration on the counts of antral follicles, corpora lutea, preovulatory follicles, and atretic follicles are shown. Compared to the control group, the BPA group showed an increment in the mean count of atretic follicles, while the antral follicles decreased $(P \leq 0.05)$. The BPA group also showed a lower number of corpora lutea $(P \leq 0.05)$, while in BPA + Aloe vera, alterations due to BPA exposure were significantly $(P \leq 0.05)$ compensated to that of the control level. There were no significant differences noted in the total mean count of the primary, secondary, and primordial follicles between the study groups $(P>0.05)$.

Table 5 presents the effects of unaccompanied BPA exposure and BPA exposure with Aloe vera administration on the diameters $(\mu)$ of antral follicles, corpora lutea, preovulatory follicles, and atretic follicles. Accordingly, BPA exposure significantly decreased the diameter of antral follicles compared to that of the control group $(P \leq 0.05)$, while no significant differences were observed in the diameters of primordial, primary, secondary, atretic follicles, and corpora lutea between the groups $(P>0.05)$. In BPA + Aloe vera, the diameter of antral follicle was compensated to the control level.

Histopathological findings: The structure of the ovarian tissue was found to be normal in control, olive oil and Aloe vera groups (Figure 1). The number of atretic follicles increased in the BPA group (Figure 2). In addition, multiple cystic follicles (ovulatory follicles) with a thin granulosa layer and no measurable theca were detected (Figure 3). There was no significant variation in the ovary tissue of the BPA+Aloe vera group compared to that of the control (Figure 4).

Table 1 . Mean \pm SD of the ovary weight and body weight of rats in different groups

\begin{tabular}{cccc} 
Parameter & Weight of ovary $(\mathrm{g})$ & Bodyweight $(\mathrm{g})$ \\
& Group1 & $0.48 \pm 3.4$ & $243 \pm 3.2$ \\
& Group2 & $0.49 \pm 4.1$ & $237 \pm 6.4$ \\
Group3 & $2.9 \pm 0.46$ & $251 \pm 6.4$ \\
Group4 & $0.39 \pm 6.1$ & $234 \pm 4.4$ \\
\hline
\end{tabular}

Table 2. Mean \pm SD of the sex steroid hormones of rats in different groups

\begin{tabular}{|c|c|c|c|}
\hline Groups & Parameter & 17 beta estradiol (ng/ml) & Progesterone (ng/ml) \\
\hline & Group1 & $34.8 \pm 4.4^{\mathrm{a}}$ & $3.2 \pm 16.48$ \\
\hline & Group2 & $33.2 \pm 3.7^{\mathrm{a}}$ & $15.9 \pm 3.7$ \\
\hline & Group3 & $34.5 \pm 4.3^{\mathrm{a}}$ & $15.8 \pm 2.5$ \\
\hline & Group4 & $19.9 \pm 3.1^{b}$ & $4.1 \pm 13.11$ \\
\hline & Group5 & $31.6 \pm 2.5^{\mathrm{a}}$ & $2.9 \pm 14.93$ \\
\hline
\end{tabular}

${ }^{\mathrm{a}},{ }^{\mathrm{b}}$ in each column indicate significant differences at $P<0.05$. 
Table 3. Mean \pm SD of the malondialdehyde (MDA), thiol protein (GSH) and total antioxidant capacity (TAC) levels of rats in different groups

\begin{tabular}{cccc}
\hline Proups & MDA $\left.(\mathrm{nmol} \mathrm{mL})^{-1}\right)$ & G-SH $\left(\mu \mathrm{mol} \mathrm{mL}^{-1}\right)$ & TAC \\
Group1 & $4.31 \pm 1.31^{\mathrm{b}}$ & $437.9 \pm 1.3^{\mathrm{b}}$ & $451.3 \pm 2.3^{\mathrm{b}}$ \\
Group2 & $4.54 \pm 3.1^{\mathrm{b}}$ & $445.6 \pm 4.5^{\mathrm{b}}$ & $449.3 \pm 4.3^{\mathrm{b}}$ \\
Group3 & $2.14 \pm 3.2^{\mathrm{c}}$ & $789.9 \pm 2.2^{\mathrm{c}}$ & $533.31 \pm 6.4^{\mathrm{c}}$ \\
Group4 & $7.21 \pm 2.7^{\mathrm{a}}$ & $298 \pm 2.1^{\mathrm{a}}$ & $308.11 \pm 2.1^{\mathrm{a}}$ \\
\hline Group5 & $4.62 \pm 0.6^{\mathrm{b}}$ & $466.5 \pm 6.7^{\mathrm{b}}$ & $438.5 \pm 6.1^{\mathrm{b}}$ \\
\hline
\end{tabular}

${ }^{\mathrm{a}},{ }^{\mathrm{b}},{ }^{\mathrm{c}}$ in each column indicate significant differences at $P<0.05$.

Table 4. Mean \pm SD of the number of primordial, primary, secondary, antral, and atretic follicles of rats in different groups

\begin{tabular}{ccccccc} 
Parameter & Primordial & Primary & Secondary & Antral & Atretic & Corpus luteum \\
\hline Groups & $3.63 \pm 2.4$ & $2.57 \pm 4.1$ & $5.56 \pm 3.7$ & $0.86^{\mathrm{a}} \pm 1.4$ & $3.7^{\mathrm{a}} \pm 3.2$ & $9.7^{\mathrm{a}} \pm 2.1$ \\
Group2 & $3.66 \pm 3.8$ & $2.44 \pm 1.2$ & $5.64 \pm 2.5$ & $0.69^{\mathrm{a}} \pm 2.2$ & $3.8^{\mathrm{a}} \pm 2.5$ & $11.1^{\mathrm{a}} \pm 3.4$ \\
Group3 & $3.49 \pm 4.1$ & $2.8 \pm 2.4$ & $5.47 \pm 3.1$ & $0.82^{\mathrm{a}} \pm 2.3$ & $3.5^{\mathrm{a}} \pm 4.3$ & $10.4^{\mathrm{a}} \pm 2.3$ \\
Group4 & $3.11 \pm 1.9$ & $2.23 \pm 3.4$ & $4.78 \pm 3.6$ & $0.44^{\mathrm{b}} \pm 2.6$ & $5.7^{\mathrm{b}} \pm 2.1$ & $4.9^{\mathrm{b}} \pm 2.5$ \\
Group5 & $3.19 \pm 2.5$ & $2.31 \pm 2.4$ & $4.98 \pm 1.9$ & $0.7^{\mathrm{a}} \pm 3.6$ & $3.3^{\mathrm{a}} \pm 2.1$ & $8.2^{\mathrm{a}^{\mathrm{a}} \pm 4.1}$ \\
\hline
\end{tabular}

${ }^{\mathrm{a}}, \mathrm{b}$ in each column indicate significant differences at $P<0.05$.

Table 5. Mean \pm SD of the diameter of primordial, primary, secondary, antral, and atretic follicles of rats in different groups

\begin{tabular}{ccccccc}
\hline Proups & Primordial & Primary & Secondary & Antral & Atretic & Corpus luteum \\
\hline Group1 & $31.53 \pm 1.7$ & $48.36 \pm 3.6$ & $287.9 \pm 3.3$ & $781.3^{\mathrm{a}} \pm 2.5$ & $850.3 \pm 1.5$ & $971.3 \pm 2.4$ \\
Group2 & $31.56 \pm 2.9$ & $45.16 \pm 2.9$ & $290.7 \pm 2.3$ & $772.9^{\mathrm{a}} \pm 3.1$ & $862.7 \pm 1.6$ & $925.8 \pm 3.1$ \\
Group3 & $31.45 \pm 1.4$ & $46.71 \pm 1.7$ & $278.2 \pm 2.8$ & $780.7^{\mathrm{a}} \pm 4.2$ & $847.4 \pm 3.3$ & $990.4 \pm 3.5$ \\
Group4 & $28.06 \pm 3.9$ & $39.5 \pm 1.5$ & $256.1 \pm 2.8$ & $377.5^{\mathrm{b}} \pm 2.3$ & $842.9 \pm 4.1$ & $923.4 \pm 3.4$ \\
Group5 & $30.09 \pm 3.2$ & $42.32 \pm 2.7$ & $260.7 \pm 5.1$ & $655.3^{\mathrm{a}} \pm 2.4$ & $845.3 \pm 3.5$ & $902.5 \pm 5.1$ \\
\hline
\end{tabular}

${ }^{\mathrm{a}},{ }^{\mathrm{b}}$ in each column indicate significant differences at $P<0.05$.

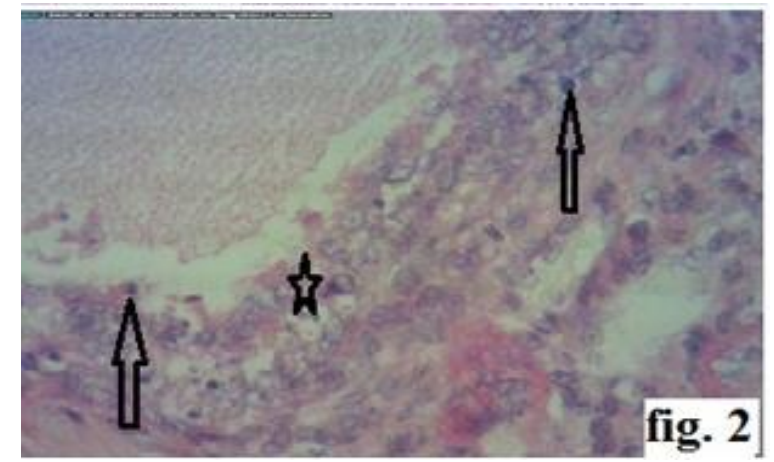

Figure 2. Light photomicrographs of the ovary in BPA group $(H \& E \times 400)$. Atresian follicle with dense and picnotic nuclei and segregation in granulosa cells. Arrows: dense and picnotic nuclei. Star: segregation in granulosa cells.

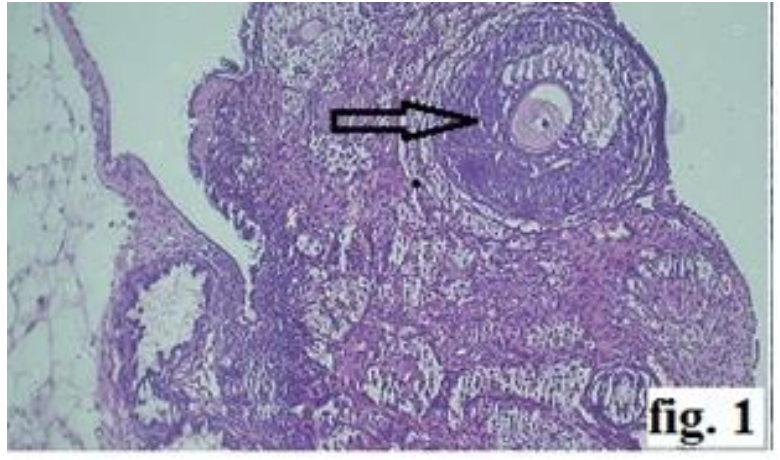

Figure 1. Light photomicrographs of the ovary in control group $(H \& \mathbf{E} \times \mathbf{4 0})$. The structure of the ovarian tissue is normal. Arrow: secondary follicle. 


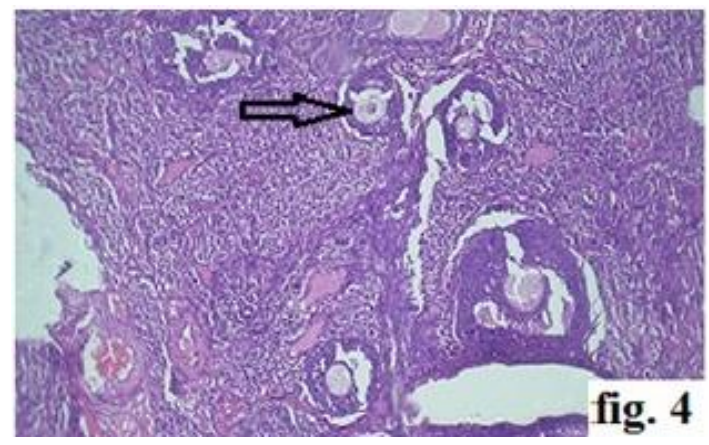

Figure 4. Ovary tissue of BPA+ Aloe vera group (H\&E $\times 40)$. The structure of the ovarian tissue is normal. Arrow: secondry follicle.

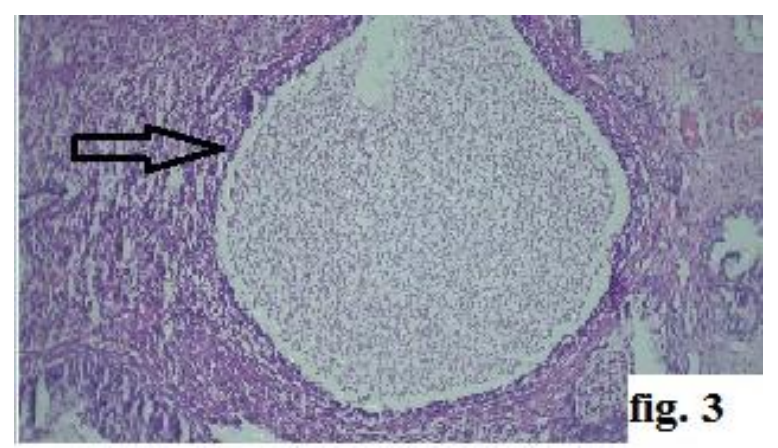

Figure 3. Light photomicrographs of the ovary in BPA group $(H \& E \times 100)$. Cystic follicles with a thin granulosa layer and no detectable theca. Arrow: cystic follicle.

\section{Discussion}

Bisphenol A, which is a chemical compound, infiltrates the environment due to continuous distribution. BPA exposure is a significant predisposing factor to oxidative tissue damage, which could be alleviated by antioxidants. Aloe vera has antioxidant properties that might be beneficial for decreasing the toxic effect of BPA. However, there is no investigation concerning the effect of Aloe vera on BPA induced oxidative stress in the ovary. The present study aimed to investigate the possible risk of ovary alterations as a result of BPA exposure, and therefore, the potential useful impact of Aloe vera in protection against BPA elicited ovary damage. Our findings indicated no significant difference in the body weight of animals with BPA exposure compared to the control group. Similar results were obtained in some studies such as Bindhumol et al. (13). However, this result contrasts with studies indicating BPA body weight decrease in animals $(14,15)$. In agreement to previous reports $(16,17)$, we found that ovarian weight was not modified by BPA exposure. In this study, histological analysis also suggested that in the experimental group treated with BPA, Fernándezet et al. reported similar data concerning the increase of atretic follicle numbers and decrease of antral follicles and corpus luteum (18). Furthermore, according to the present study, BPA decreased hormone production in the rat's ovary antral follicle. Jackye Peretz et al. (19) claimed that the reduction of rate-limiting enzymes, such as StAR and $\mathrm{P} 450$ scc, in the follicles could lead to BPA-induced inhibition of steroidogenesis and follicle growth, as such enzymes are involved in follicle growth in affecting the pathways of estradiol biosynthesis. Estradiol is a sex hormone that plays a key role in the stimulation of follicle growth and follicle protection against atresia (20). The coadministration of BPA with Aloe vera compensated for the quantity of atretic follicles, antral follicle, and corpus luteum to that of the control level. The improvement could be due to a reduction in lipid peroxidation and an increase in the antioxidant capacity (24). It could also be due to Aloe vera, which contains compounds that can increase estrogen levels (21). The presented data revealed that BPA-induced oxidative and toxic damage can be decreased by antioxidants. It has been well-established that Aloe vera's remarkable antioxidant activities could lead to the diminishment of BPA toxicity. Other studies have also investigated this hypothesis by using similar plants with antioxidant activities $(22,23)$. According to the findings of this current research, the diameter of the antral follicle reduced with exposure to BPA, in comparison to other groups because BPA induced apoptosis in granulosa cells (24) and decreased zona pellucid thickness (18). As mentioned above, this may be due to the reduction in the level of estradiol hormone which inhibits the growth of antral follicles. This finding is in agreement with the results of Fernándezet et al. (18). The diameter of antral follicles was also compensated to the control level following co-administration of BPA and Aloe vera. This can be due to the function of Aloe vera in the increase of ovarian steroidogenesis and serum estrogen concentration, which is in agreement with the findings of Telefo et al. (25). Since Aloe vera plant extract has similar effects on follicle-stimulating hormones, it can cause an increase in follicle growth and development in a similar manner (26). According to histopathological findings, there were multiple cysts in animals in the BPA group, and several of the atretic follicles were found to be cystic and were similar to the detected cysts of PCOS animal models. The results obtained by Takeuchi et al. (27) are consistent with the current research in regards to ovary changes. Correspondingly, BPA exposure could be a contributing factor to hyper-androgenaemia, which is considered to be a marked diagnostic feature of PCOS. Hormonal dysfunction is a probable cause of this problem. The administration of Aloe vera extract caused a reduction in cysts and there was no significant variation in the ovary tissue of the BPA+Aloe vera group compared to the control group. According to Poorfarid et al. (21), this restoration is due to the positive fertility effects of the plant.

\section{Conclusion}

The results of this study demonstrated that BPA can reduce folliculogenesis. The study also provided further evidence on the oxidative and hormonal adversive effects of BPA on the ovaries which can lead to infertility. Aloe vera extract treatment through its 
antioxidant activity and regulation of sex hormones, can compensate for the stated adverse effects. It is shown that Aloe vera can have beneficial and supportive effects on ovarian tissues and folliculogenesis.

\section{Acknowledgements}

The authors would like to acknowledge Dezful University for its financial support. No potential conflict of interest was reported by the authors.

\section{Conflict of Interest}

Authors declared no conflict of interests.

\section{References}

1. Rubin BS. Bisphenol A: an endocrine disruptor with widespread exposure and multiple effects. J Steroid Biochem Mol Biol. 2011; 127(1-2): 27-34. [DOI:10.1016/i.jsbmb.2011.05.002] [PMID]

2. Soleimani Mehranjani M, Mansoori T. Stereological study on the effect of vitamin $\mathrm{C}$ in preventing the adverse effects of bisphenol A on rat ovary. Int J Reprod Biomed. 2016; 14(6): 403-10. [DOI:10.29252/ijrm.14.6.403]

3. Korkmaz A, Aydoğan M, Kolankaya D, Barlas N. Vitamin C coadministration augments bisphenol A, nonylphenol, and octylphenol induced oxidative damage on kidney of rats. Environment Toxicol. 2011; 26(4): 325-37. [DOI:10.1002/tox.20556] [PMID]

4. Modaresi M, Khodadadi A. The effects of aloe vera extract on reproductive parameters in mice. International Conference on Biological, Environment and Food Engineering. 2014; 2014: 15-14.

5. Behmanesh MA, Najafzadehvarzi H, Poormoosavi SM. Protective Effect of Aloe vera Extract against Bisphenol A Induced Testicular Toxicity in Wistar Rats. Cell J. 2018; 20(2): $278-83$.

6. Lee KH, Kim JH, Lim DS, Kim CH. Anti-leukaemic and antimutagenic effects of Di (2-ethylhexyl) phthalate isolated from Aloe vera Linne. J Pharm Pharmacol. 2000; 52(5):593-8. [DOI:10.1211/0022357001774246] [PMID]

7. Radha MH, Laxmipriya NP. Evaluation of biological properties and clinical effectiveness of Aloe vera: A systematic review. J Tradit Complement Med. 2014; 5(1): 21-6. [DOI:10.1016/j.jtcme.2014.10.006] [PMID] [PMCID]

8. Ooe $\mathrm{H}$, Taira $\mathrm{T}$, Iguchi-Ariga $\mathrm{SM}$, Ariga $\mathrm{H}$. Induction of reactive oxygen species by bisphenol $\mathrm{A}$ and abrogation of bisphenol A-induced cell injury by DJ-1. Toxicol Sci. 2005; 88(1): 114-26. [DOI:10.1093/toxsci/kfi278] [PMID]

9. Behmanesh MA, Efani Majd N, Shahriari A, Nnajafzadeh H. Evaluation of antioxidant potential of Aloe vera and pituitary sexual hormones after experimental diabetes in male rats. Iran J Vet Med. 2017; 11(2): 164-74.

10. Abdel-Wahab WM. Thymoquinone attenuates toxicity and oxidative stress induced by bisphenol $\mathrm{A}$ in liver of male rats. Pak J Biol Sci. 2014; 17(11): 1152-60. [DOI:10.3923/pjbs.2014.1152.1160] [PMID]

11. Nielsen F, Mikkelsen BB, Nielsen JB, Andersen HR, Grandjean P. Plasma malondialdehyde as biomarker for oxidative stress: reference interval and effects of life-style factors. Clin Chem. 1997; 43(7): 1209-4.

12. Beutler E., Duron O, Kelly BM. Improved method for determination of blood glutathione. J Lab Clin Med. 1963; 61: 882-8.

13. Bindhumol V, Chitra KC, Mathur PP. Bisphenol A induces reactive oxygen species generation in the liver of male rats. Toxicol. 2003; 188(2-3): 117-24. [DOI:10.1016/S0300483X(03)00056-8]

14. Nanjappa MK, Simon L, Akingbemi BT. The industrial chemical bisphenol A (BPA) interferes with proliferative activity and development of steroidogenic capacity in rat Leydig cells. Biol Reprod. 2012; 86(5): 135, 1-12. [DOI:10.1095/biolreprod.111.095349] [PMID] [PMCID]

15. Yamasaki K, Sawaki M, Noda S, Imatanaka N, Takatsuki M. Subacute oral toxicity study of ethynylestradiol and bisphenol A, based on the draft protocol for the "Enhanced OECD Test Guideline no. 407". Arch Toxicol. 2002; 76(2): 65-74. [DOI:10.1007/s00204-001-0319-1] [PMID]

16. Gámez J, Penalba R, Cardoso N, Bernasconi PS, Carbone S, Ponzo O,et al. Exposure to a low dose of bisphenol A impairs pituitary-ovarian axis in prepubertal rats: effects on early folliculogenesis. Environ Toxicol Pharmacol. 2014; 39(1): 915. [DOI:10.1016/i.etap.2014.10.015] [PMID]

17. Evans NP, North T, Dye S, Sweeney T. Differential effects of the endocrine-disrupting compounds bisphenol-A and octylphenol on gonadotropin secretion, in prepubertal ewe lambs. Domest Anim Endocrinol. 2004; 26(1): 61-73. [DOI:10.1016/j.domaniend.2003.09.005] [PMID]

18. Fernández M, Bourguignon N, Lux-Lantos V, Libertun C. Neonatal exposure to bisphenol a and reproductive and endocrine alterations resembling the polycystic ovarian syndrome in adult rats. Environ Health Perspect. 2010; 118(9): 1217-22. [DOI:10.1289/ehp.0901257] [PMID] [PMCID]

19. Peretz J, Gupta RK, Singh J, Hernández-Ochoa I, Flaws JA. Bisphenol A impairs follicle growth, inhibits steroidogenesis, and downregulates rate-limiting enzymes in the estradiol biosynthesis pathway. Toxicol Sci. 2010; 119(1): 209-17. [DOI:10.1093/toxsci/kfq319] [PMID] [PMCID]

20. Quirk S, Cowan R, Harman R, Hu C-L, Porter D. Ovarian follicular growth and atresia: the relationship between cell proliferation and survival. J Anim Sci. 2004; 82: E40-E52. [DOI:10.2527/2004.8213_supplE40x] [PMID]

21. Poorfarid M, Karimi Jashni H, Houshmand F. The effects of Aloe Vera sap on progesterone, estrogen and gonadotropin in female rats. J Jahrom Univ Med Sci. 2012; 10(4): 7-12. [DOI:10.29252/jmj.10.4.7]

22. Gaikwad K, Dhande S, Joshi YM, Kadam V. Protective effect of Adiantum capillus against chemically induced oxidative stress by cisplatin. J Appl Pharm Sci. 2013; 3(2): 65-68.

23. Akingbemi BT, Sottas CM, Koulova AI, Klinefelter GR, Hardy MP. Inhibition of testicular steroidogenesis by the xenoestrogen bisphenol A is associated with reduced pituitary luteinizing hormone secretion and decreased steroidogenic enzyme gene expression in rat Leydig cells. Endocrinology. 2004; 145(2): 592-603. [DOI:10.1210/en.2003-1174] [PMID]

24. Xu J, Osuga Y, Yano T, Morita Y, Tang X, Fujiwara T,et al. Bisphenol A induces apoptosis and G2-to-M arrest of ovarian 
granulosa cells. Biochem Biophys Res Commun. 2002; 292(2): 456-62. [DOI:10.1006/bbrc.2002.6644] [PMID]

25. Telefo P, Moundipa P, Tchouanguep FM. Inductive effect of the leaf mixture extract of Aloe buettneri, Justicia insularis, Dicliptera verticillata and Hibiscus macranthus on in vitro production of estradiol. J Ethnopharmacol. 2004; 91(2-3): 22530. [DOI:10.1016/S0378-8741(04)00022-4]

26. Kosif R, Akta G, Öztekin A. Microscopic examination of placenta of rats prenatally exposed to Aloe barbadensis: A preliminary study. Int J Morphol. 2008; 26(2): 275-81. [DOI:10.4067/S0717-95022008000200005]

27. Takeuchi T, Tsutsumi O, Ikezuki Y, Takai Y, Taketani Y. Positive relationship between androgen and the endocrine disruptor, bisphenol A, in normal women and women with ovarian dysfunction. Endocrine J. 2004; 51(2): 165-9. [DOI:10.1507/endocr. 51.165]

\section{How to Cite This Article:}

Behmanesh M A, Poormoosavi M, Jannati S, Najafzadeh Varzi H, Sangtarash E. Aloe Vera Ameliorates Ovarian Toxicity Induced by Bisphenol A in Wistar Rats. J Adv Med Biomed Res. 2018; 26 (119) :17-23

\section{Download citation:}

BibTeX $|\underline{\text { RIS }}| \underline{\text { EndNote }}|\underline{\text { Medlars }}| \underline{\text { ProCite }}|\underline{\text { Reference Manager }}| \underline{\text { RefWorks }}$

\section{Send citation to:}

\$. Mendeley 2 Zotero (i) RefWorks RefWorks 